(p. 20). Then again, on p. 179, "These two separated hydrogen atoms, with their natural affinities now loose and unsatisfied, were eager for any kind of union". It is surely difficult for any scientific investigator to tell whether or no atoms are 'eager'. There is also the customary carelessness in using technical philosophical terms. In spite of these slight blemishes, the volume can be very strongly recommended.

(2) The scope of the second volume, "Frontiers of Science" by C. T. Chase, is very similar. Yet in spite of its excellent illustrations, the account is much less vivid. To the reviewer it savours more of the atmosphere of the science library than of the research laboratory itself. If popular science writers insist on using animistic explanations in physics, would it not help to push the method to its logical conclusion? Mr. Gray's atoms can be 'eager'; Mr. Chase's electrons can 'make decisions'. "What happens when an electron decides to break away from an atomic nucleus?" (p. 249).

(3) Instead of bringing animistic explanations up to date by giving atoms and electrons instincts or Edipus complexes and the like, Prof. Richards in "The Universe Surveyed" seems, on p. 5, to go back to the early appeal to what is 'natural', giving, incidentally, vectorial qualities to hydrostatic pressure. "It is natural for water to run down hill. This is a consequence of the tendency of water to flow in the direction of the greater pressure." The writing is so 'bright' that it is sometimes difficult to tell which passages are offered as explanations and which as rhetorical devices planned to ridicule.

'Why' questions are frequently asked. "Why do we fall when the foot-bridge breaks under us ? . . . the answer itself, when finally discovered, was found to link us with the stars" (p. 17). Such a passage is apt to give the impression that the scientific investigator can answer 'Why' questions and moreover that the finality of a scientific explanation can be determined. The most noteworthy features of the book are its many excellent illustrations and the inclusion of a section on geology. The title is much too comprehensive in that the universe surveyed is chiefly the non-biological part of the universe. Even vitamins and hormones are treated chiefly from the chemical point of view and psychology is barely mentioned.

The outstanding excellence of Mr. Gray's book overshadows all except the illustrations of the other two volumes.
W. H. GEORGE.

\title{
Human Ecology
}

\section{Life as a Whole}

By Dr. J. W. Bews. Pp. ix + 347. (London, New York and Toronto: Longmans, Green and Co., Ltd., 1937.) 15s. net.

DROF. BEWS' book is very difficult to review and, but for the evidence of the accom. plished fact, might have been thought impossible to write. It is intended to supplement his previous work "Human Ecology", which was a study of man in relation to his environment-material, social and cultural. The present work is an attempt at a more complete synthesis. It is written explicitly from the point of view of General Smuts's theory of 'Holism'. The development of mankind is considered as the construction or creation of new 'wholes', whether these are mechanical inventions, social institutions, scientific and philosophical theories, or works of art. The author's general conclusion is that all human constructions are imperfect and may have to be pulled down and reconstructed. The pulling down may necessitate temporary reversion to more primitive and simpler conditions.

Perhaps the least satisfactory parts of the book are the chapters dealing respectively with social life and institutions, history and philosophy, art, architecture, music, literature. Twenty pages or so are devoted to describing the endeavours of the whole human race in each of these directions. The reader who knows about the subject is likely to be exasperated and the reader who does not bewildered. At almost any point he will be likely to ask: Why is this put in and why is that left out?

One does not know whether to praise Prof. Bews for his courage or condemn him for his rashness. Yet it is hard to see what else he could do. If the chapters had been expanded to two hundred pages or contracted to two, it would probably have been worse. That is one of the reasons why a book of this kind seems impossible to write.

The earlier chapters, the subject-matter of which may be roughly indicated by the term social psychology, are more satisfactory. Occasionally Prof. Bews may have chosen to follow opinions of doubtful reliability, but as he quotes his authorities this cannot do much harm. In any event we should be grateful to one who brings to his survey of mankind moderation, reason and sanity, at a time when these virtues are being extinguished in many quarters.

A. D. R. 